IRA-International Journal of Education \& Multidisciplinary Studies

ISSN 2455-2526; Vol.05, Issue 01 (2016)

Pg. no. 22-38

Institute of Research Advances

http://research-advances.org/index.php/IJEMS

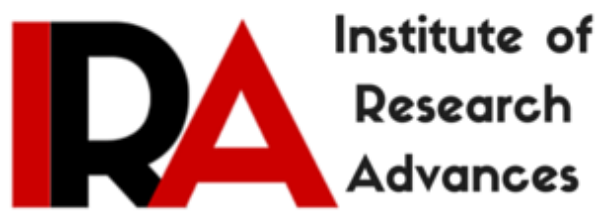

\title{
The Acquisition of Parameters for Word Stress Production and Perception among Iraqi EFL Learners: A Pilot Study
}

${ }^{1}$ Zainab A. Ali

School of Humanities

University Sains Malaysia, Malaysia.

${ }^{2}$ Alias Abd Ghani

School of Humanities

University Sains Malaysia, Malaysia.

Type of Review: Peer Reviewed.

DOI: http://dx.doi.org/10.21013/jems.v5.n1.p4

\section{How to cite this paper:}

Ali, Z., \& Ghani, A. (2016). The Acquisition of Parameters for Word Stress Production and Perception among Iraqi EFL Learners: A Pilot Study. IRA International Journal of Education and Multidisciplinary Studies (ISSN 2455-2526), 5(1), 22-38.

doi:http://dx.doi.org/10.21013/jems.v5.n1.p4

(C) Institute of Research Advances

(c) EY-NC

This work is licensed under a Creative Commons Attribution-Non Commercial 4.0 International License subject to proper citation to the publication source of the work.

Disclaimer: The scholarly papers as reviewed and published by the Institute of Research Advances (IRA) are the views and opinions of their respective authors and are not the views or opinions of the IRA. The IRA disclaims of any harm or loss caused due to the published content to any party. 


\begin{abstract}
This study investigates the acquisition of the parameters of word stress production and perception by 10 Iraqi learners of English as a foreign language (EFL). It aims at investigating Iraqi learners' difficulties in resetting the parameters of word stress production and perception in L2. Two experiments are conducted to test the learners' production and perception of word stress in isolation and in sentences. The first experiment is the production test and the second one is the perception test. The learners' responses of word stress in both experimental tasks are elicited manually and analysed according to [7] model of metrical parameters which is used to investigate the acquisition of parameters of word stress production and perception by Iraqi learners. The findings reveal that Iraqi EFL learners are able to reset the parameters of $L 2$ but even though they failed in resetting all the parameters completely. Besides, the learners used more ranking level kinds of the parameters in the perception task than in the production task which may cause Iraqi learners assign wrongly the word stress placement.
\end{abstract}

Keywords: word stress, word production, word perception, acquisition of parameters, metrical phonology, Iraqi learners

\title{
1. Introduction
}

The topic of the acquisition of prosody in L2 is relatively under-researched, and little attention has been given to the role of phonology in second language acquisition (SLA), particularly stress in English (e.g., $[11,14,12,13,17]$. In contrast, numerous studies have focused on the role of syntax and morphology using parameterized models, such as [10] and [19] and particularly the edited papers of [9], which cover thoroughly the role of grammar in SLA.

\section{Theoretical Background}

2.1 Dresher and Kaye's (1990) Model of Metrical Parameters (Metrical Tree): Rules and Parameters

Word stress is regarded as one of the most important suprasegmental features that can affect intelligibility since it is essential in determining the word identity $[3,4]$. Stress refers to the degree of force used in the speaker's production of the syllable in the word [16].

Reference [7] outlined a number of universal parameters for constructing metrical structures that take the form of labelled trees where various possibilities are expressed in terms of a series of binary parameters. However, this study adopts the metrical parameters in [7] model where Chomsky's Government and Binding Theory [5] is part of it. This model is considered as a factual learning path for stress systems within the framework of Principles \& Parameters theory in universal grammar (UG) for the following reasons:

1) Every stage of the path is represented by each parameter and the learners try to look out for data of a particular type which are called 'cues' in which the next stage will start when the parameter of that stage arranged and these data identified.

2) The cue must be derived from the input and it must be appropriate to its parameter, i.e., it must reflect the essential features of the parameter [6]. Besides, the selection of the suitable cue for each parameter must be empirically determined by the linguist and gradually the process of parameters setting must achieve in a partial order set by UG where the dependencies will play an important role among the cues.

The relevant metrical parameters in Arabic and English are determined according to the metrical parameters of [7]. Table 1 involves the parameter values of Arabic and English language with their appropriate defaults in UG according to [7]: 
On one hand, the difference between the parameters of Arabic, specifically Modern standard Arabic (MSA) and English appears only in the value of P3, which indicates that Arabic builds its feet from left to the right. As assigned in Table 1, the default setting of P3 is left, which is the case for Arabic, whereas it is right for English. Hence, we predicted that the Iraqi L2 learners will have difficulty in resetting this parameter to its marked value in English. With regard to other parameters, we predicted that Iraqi L2 learners would not face any difficulties in resetting these parameters, that is, P1, P2, P4, P5, P8A, P8B, and P8, to their marked value in English. The metrical parameters of stress assignment in Arabic and English language are shown in Figure 1.

\subsection{The Prosodic acquisition path (PAP) of Iraqi learners in resetting the Parameters}

The parameter setting refers to a process when the two languages have different settings of the same parameter whereas those, which have the same settings for a given parameter, they involve similar settings [15].

In this study, D\&K (1990) suggested a prosodic acquisition path (PAP) to be followed by learners of L2 in resetting the parameters. Therefore, Iraqi learners were guided to follow the suggested path, one by one starting from the beginning until the end, they can set the below parameters to their correct values depending on the positive evidence and achieve the acquisition of L2. The underlined values indicate the correct setting of L2. Figure 2 below shows the prosodic hierarchy of the metrical parameters in English using tree structure to show how Iraqi learners will follow the suggested PAP in the production and perception of word stress placement (the underlined values are the correct ones in each parameter).

\subsection{Research Questions}

In order to achieve the objectives, the present study addressed the following two research questions:

1) What are Iraqi EFL learners' difficulties in resetting the word stress production and perception in L2?

2) What are the ranking level kinds of the wrong parameters used by Iraqi learners of common word stress production and perception?

\section{Methodology}

\subsection{Participants}

Ten Iraqi learners of the pilot study were selected ( 6 females, 4 males) who had studied English as a foreign language for at least 10 years and had been living in Baghdad for some time. All of them were educated in MSA and their native language was Arabic. This is why MSA was selected as a basis to obtain a homogeneous group. The learners had taken a course in phonetics and phonology, and the researcher used the scores of the learners in the second year as a measurement of the learners' ability in spoken English. Only those learners whose scores were 50 and above were selected. Choosing learners who had failing scores might have yielded results showing more L1 influence, as is suggested by some studies like [1] who assumed that selecting less advanced students could get more L1 influence in general, and it is not clear if they could overcome this influence and became sensitive to the L2 stress pattern. The learners' ages ranged from 21-28. All Iraqi learners were third year undergraduate students, and they were tested at Baghdad University, Iraq. 


\subsection{Research Instruments}

Quantitative data were collected by conducting an experimental test to examine Iraqi learners' in word stress production and perception.

\subsubsection{Experimental Items}

This study is limited to investigation only the primary stress of lexical simple words of two and three syllables, specifically verbs and nouns. The words were selected to reflect a specific aspect of English metrical parameter focusing on stress placement, for example, including that English stress is sensitive to the grammatical category of the item. The position of stressed syllable as its relation to other syllables can be determined by three categories: stress on the final syllable, stress on the penultimate (penult), i.e., prefinal syllable, and stress on the antepenultimate (antepenult), i.e., the syllable that precedes pre-final syllable. In addition, the words were tested in isolation, using a randomized word list in which the stressed syllable would be clear, and in context of a declarative sentence. The English words appeared in the final position of the sentence preceded by a non-stress bearing lexical item to avoid any possibility of a stress clash or any sort of rhythm phenomena. This methodology was adapted from [2]. The metrical stress patterns of English words represented either a match or a mismatch of the metrical parameter settings focusing on the stress placement rules for MSA and English.

\subsubsection{Experimental Tasks}

The experiment composed of two experimental tasks: the production and perception task. This methodology was adapted from [2].

\subsubsection{Experiment 1: Production task}

In the first experimental task, the Iraqi learners were examined on their production of word stress in isolation and in a sentence. In the first sub-part, the learners were asked to read a list of randomized words loudly, and in the second sub-part, the learners were asked to read a list of sentences which included each of the English words. The focus of the test was not explained to the learners; they were under the impression that their overall pronunciation was being investigated.

\subsubsection{Experiment 2: perception task}

In the second experimental task, Iraqi learners were examined on their perception of word stress in isolation and in a sentence. The learners were seated in front of a computer screen and informed that they would hear the same words and sentences in the production task spoken by a native speaker of British English. The perception test was composed of two experimental parts. In the first sub-part, the learners listened to a native speaker pronounce each of the words twice from a laptop computer. The researcher used a natural reader program to ensure that the students heard the words pronounced by a British speaker, since standard British English is normally used in Iraq. All learners underwent a training session to ensure their ability to mark the stress consistently. Once they performed correctly on three items in a row, the second task would begin. In the second sub-part, the learners listened to the sentence which included the underlined word pronounced by the British speaker, and then, s/he marked the stress on the syllable; this was repeated for the sentence-focus task. The learners were given a sheet of paper with written instructions. The learners were asked to assign the stress on the appropriate syllable of the words in isolation, as well as in sentences, on a sheet of paper when they heard the words from the recorder in the computer. Thus, the researcher elicited the learners' stress perception of the items. 
IRA-International Journal of Education \& Multidisciplinary Studies

\subsection{Data collection}

The learners' responses of the English words in the production task were elicited from the experimental group and recorded using a voice MP3 recorder, and later transcribed using the Praat software program. As for the learners' perception responses, they are manually marked on a paper sheet. Therefore, the researcher elicited the learners' responses of word stress production and perception of the items. Besides, the researcher checked the prominent stressed syllable of each word produced and perceived by the sample learners with the assistance of a lecturer at university of Baghdad who like-native speaker of English (fluent in English and Arabic).

\subsection{Data Analysis}

Mixed methods are used to analyse Iraqi learners' word stress production and perception. The responses of Iraqi learners' word stress production and perception task are analysed statistically to investigate the learners' incorrect responses in word stress production and perception. Then, the most common incorrect responses of the learners' word stress placement in each class are selected to be analysed qualitatively according to the metrical parameters in the adapted model of [7]. This is important to investigate the wrong parameters with their ranking level kinds used by Iraqi learners in their producing and perceiving the word stress placement which will then help in understanding the reasons behind their difficulties in word stress placement.

\subsection{Results and Discussion}

\subsubsection{Results of Iraqi learners' incorrect responses in resetting the parameters of word stress production and perception}

\section{Classes 1 and 2}

Table 2 shows the percentages of correct and incorrect stress patterns in classes 1 and 2 ( wpro stands for word production, spro stands for sentence production, wper stands for word perception, and sper stands for sentence perception).

Statistically, two tailed t-tests were conducted to see if there was any significant difference between wpro vs. spro, and wper vs. sper. As for class 1, there was no significant difference between them in the performance of the learners since the values $\geq 0.05$ ( $\mathrm{sig}$. $=.193$ and .168 respectively). Statistically, there was also no significant difference in the performance of the learners between Wpro and Wper (sig. = .057) whereas the values revealed a significant difference $($ sig. $=001)$ between Spro and Sper, and the learners had more difficulty in Sper than in Spro. As for class 2, With regard to Wpro vs. Spro and Wper vs. Sper, the statistical results show that there was no significant difference in the performance of the learners as the values indicate (sig. $=.822$ and .394 , respectively). As for Wpro vs. Wper and Spro vs. Sper, the values also show that there was no significant difference in the performance of the learners as the values indicate (sig. $=.051$ and .138 , respectively).

\section{Classes 3, 4, and 5}

Table 3 shows the percentages of correct and incorrect stress patterns in class 3, 4 and 5. With regard to class (3), two-tailed t-tests were used to see if there is any significant difference between Wpro and Spro and also between Wper and Sper. The statistical results show that there was no significant difference in the performance of the learners as the values indicate (sig. $=.042$ and .726 respectively). With regard to Wpro vs. Wper, there was no significant difference in the performance of the learners as the values 
indicate $($ sig. $=.070)$ whereas Spro vs. Sper indicated a significant difference $($ sig. $=001)$. This means that the learners have more difficulty in Spro than in Sper.

As for class 4, pairing the results of Wpro and Spro and Wper and Sper in class (4) Table (20), as well as between Wpro and Wper and Spro and Sper (sig. .193 and .223, respectively), we found no significant difference in the performance of learners. As for class 5, two-tailed t-tests were conducted to see if there was any significant difference between Wpro and Spro, and Wper and Sper. There was no significant difference between them, as the values indicate (sig. 1.000 and .168 respectively). The same results showed no significant difference in pairing Wpro and Wper, but there was a significant difference in pairing Spro and Sper (sig. .299 and .001, respectively). This indicates that the performance of the learners was better in Sper than Spro.

\section{Classes 6 and 7}

Table 4 shows the percentages of correct and incorrect stress patterns in classes 6 and 7. The statistical results reveal that there is no significant difference between wpro vs. spro, and wper vs. sper as well as between Wpro vs. Wper and Spro vs. Sper as all the values are more than 0.05 in classes 6 and 7 .

Generally, on one hand, two-tailed t-tests were conducted to analyse the seven classes to see if there was any significant difference between the two tasks. There was no significant difference in the performance of the learners concerning the production and perception tasks (sig. $=.175$ and .048 , respectively). On the other hand, an Anova was conducted to see if there was any significant difference between Wpro vs. Spro and Wper vs. Sper of the seven classes. The results show a significant difference in Wpro, Spro, and Sper (Sig. =. 021, .000, .003 respectively), whereas no significant difference was found in Wper (sig. $=.157$ ). This shows that the learners have performed better in Wper than Wpro, Spro, and Sper, and they have more difficulties in Spro than in Wpro and Sper.

\subsubsection{Results of the wrong parameters used by Iraqi learners in resetting the parameters of common word stress production and perception}

Table 5 displays the percentages of the common incorrect responses of stress placement for learners' word production and perception in all the classes. On one hand, the most common stress placement of the learners in the production task when they assigned wrongly the stress on the penult syllable in classes 1 , 2, 6 and 7 and antepenult syllable in classes 3, 4, and 5. On the other hand, the most common stress placement of the learners in the perception task when they assigned wrongly the stress on the final syllable in classes 1,2,3, 4, and 5 and on the penult and antepenult syllable in classes 6 and 7 respectively.

In the production of the penult stress, the learners wrongly reset the values of the parameters of Hd to the Rt and Dr from the Lt in classes 1 and 2. As regards the classes 6 and 7, the learners wrongly reset the Em (no-to-yes) with Dr Lt for bisyllabic words and Hd Rt for trisyllablic words. Figure 3 shows the syllable structures of the words when the learners produced wrongly the penult stress. Gradually, in the production of the antepenult stress, the learners wrongly reset the value of the parameter of Dr Lt in classes 3, 4, and 5. Figure 4 shows the syllable structures of the words when the learners produced wrongly the antepenult stress.

In the perception of the final stress, the learners wrongly reset the values of the parameters of Em (yes-tono) with Hd Rt for words ending with a light syllable and Dr Lt for words ending with a heavy syllable in classes 1, 2, 3, 4 and 5. Figure 5 shows the syllable structures of the words when the learners perceived wrongly the final stress. Gradually, in the perception of the penult stress, the learners wrongly reset the 
values of the parameters of Em (no-to-yes) and Dr Lt in class6. In the perception of the antepenult stress in class 7, the learners wrongly reset the values of Em (no-to-yes) with Dr Lt. Figure 6 shows the syllable structures of the words when the learners perceived wrongly the penult and antepenult stress in (a) and (b) respectively.

The percentages of the common incorrect responses of word stress production and perception in relation to the wrong values of the parameters used by Iraqi learners in acquiring L2 in both tasks for all the classes are summarized in Table 6.

On one hand, the learners reset the parameters in the production of the penult and antepenult stress better than the perception task of the final stress in classes 1,2,3,4,5. On the other hand, the learners reset the parameters in the perception of the penult and antepenult stress better than the production of the penult stress in classes 6 and 7. This reveals that learners have difficulties in perceiving more than producing the word stress placement. This result is in line with [20], whose learners' performance were better in the production than in the perception task but it against to [2] results; his learners' performance were better in perception than in the production task.

Moreover, it is noticed that learners reset wrongly the Dr Lt in all the classes in both tasks which may reveal the influence of L1 or default value. However, the negative setting values of Dr parameter in L1 and L2 can impede the production of word stress [8]. This result agrees with [20]study who reported that the learners of L2 applied the unmarked value of the Dr parameter rather than the marked one but it is difficult to decide whether it was belong to the L1 or default value since both of them have the same values. As for $\mathrm{Hd}$ and Em parameters, the learners reset wrongly the $\mathrm{Hd}$ parameter in the perception task more than the production task. Interestingly, the learners neglected the Em only in the perception task while they applied the Em on the final consonant of the words in classes 6 and 7 where it was no Em in either L1 or L2. Therefore, the learners commonly ignored Em feature in the perception task and they transferred their L1 strategy when they stressed the long vowel in the final syllable of the words recognize, baritone and antelope since they stressed the superheavy in their L1 Arabic. This is commonly found in most studies like [1] whose Arabic participants lengthened the final syllable of the words.

\subsubsection{Results of the ranking level kinds of the wrong parameters used by Iraqi learners in resetting the parameters of common word stress production and perception}

Table 7 shows the percentages of the ranking level kinds of the wrong metrical parameters used by Iraqi learners' common word stress production and perception in all the classes.

A look at Table above, the percentage of the two kinds ranking levels (embedding and terminal parameters) in the perception task are higher than in the production task. This is because that learners used $(92.85 \%)$ of both levels in the former while they used $(49.99 \%)$ of both levels in the latter. Besides, the learners reset the equal values of the $(\mathrm{Lt} / \mathrm{Rt})$ in the perception task more than in the production task since they used $(71.42 \%)$ of them in the former and $(7.14 \%)$ in the latter. The incidence of unmarked value ( $\mathrm{Lt}$ ) in the production task is more than the perception task since its percentage is $(50 \%)$ in the former while in the latter it is $(14.28 \%)$. As regards the marked value (Rt), the learners used $(14.28 \%)$ in the production task while they did not use it in the perception task since its percentage is $(0$ $\%)$. This reveals that the learners reset the marked value even it is a difficult value. The incidence of the (Em-yes) in both tasks is $(28.57 \%)$ while the occurrence of the (Em-No) in the production task is $(0 \%)$ which is less than the perception task $(71.42 \%)$ 


\subsection{Conclusions}

In the light of the previous discussion, the major conclusions of this study are as follows:

1) The findings of this study show how the principles and parameters of [7]model enable us to explain the acquisition of parameters of word stress placement in L2, and it paves the way to understanding the reasons behind the difficulties of Iraqi learners in producing and perceiving word stress placement in English language with reference to Arabic language.

2) The statistical results show that there is no significant difference between Iraqi learners' production and perception of word stress. Besides, the learners have performed better in word perception than word production, sentence production and sentence perception and they have difficulties in sentence production more than word production and sentence perception.

3) It is noticed that terminal parameters are not easier to reset than embedding parameters since the Iraqi learners used both kinds of the level kinds in both tasks. Besides, the learners used more ranking level kinds of the parameters in the perception task than in the production task which may cause difficulties in word stress placement.

\section{References}

Altmann, H. (2006). The Perception and Production of Second Language stress: A cross LinguisticExperimental Study, Unpublished Doctoral Dissertation. University of Delaware.

Archibald, J . (1993). Language Learnability and L2 Phonology: the acquisition of metrical Parameters. London: Kluwer Academic publishers.

Avery , P. \& Ehrich, S . (1992). Teaching American English Pronunciation. Oxford: Oxford University Press.

Benrabah , M .(1997), "Word stress- A source of Unintelligibility in English ", IRAL. Vol.37, no.3, 157163.

Chomsky, N . (1981). Lectures on Government and Binding. Dordrecht: Fortis.

Dresher, B. E. (1999). Charting the Learning Path: Cues to Parameter Setting. Linguistic Inquiry, 30(1), pp. 27-67.

Dresher, B. E. \& Kaye, J. (1990). A Computational Learning Model for Metrical Phonology. Cognition, 34, 137-195.

Flege, J.E. (1993). Production and perception of a novel, second-language phonetic contrast. Journal of the Acoustical Society of America, 93, 1589-1608.

Flynn, S., Martohardjono, W. \& O'Neil, G. (1998). Generative Study of Second Language Acquisition. America: Inc.

Hilles, S. (1986). Interlanguage and the Pro-drop Parameter. Second Language Research, 2, 33-52. 
Hochberg, J. (1988) . The Acquisition of Word Stress Rules in Spanish. Unpublished Doctoral Thesis, Stanford University.

Nguyen, A. \& Ingram , J.( 2005). Vietnamese Acquisition of English Word Stress . TESOL Quarterly, Vol, 39, No. 2, 309-319.

Özçelik, O. (2011). Representation and Acquisition of Stress: The case of Turkish. Unpublished Doctoral Thesis, McGill University, Canada.

Pater, J. (1992). The Acquisition of Parameters for Word Stress by French Learners of English. Unpublished Master Thesis, Concordia University: Canada.

Pas, B. \& Zonneveld, W. (2004). L2 Parameter Resetting for Metrical Systems (An assessment and a reinterpretation of some core literature). The linguistic Review, 21,125-170.

Roach, R. (2009). (2010). English Phonetics and Phonology: A practical Course. Cambridge: Cambridge University Press.

Swain, E. (2008). The Acquisition of Stress in Northern East Cree: A Case Study. Unpublished Master Thesis, Memorial University of Newfoundland.

Törkenczy, M. (2013). Word stress. In Department of English Linguistics, Eötvös Loránd University (Eds.), English phonological analysis (1-32), Retrieved at 7 June, 2015, from http://seas3. elte.hu/ phono-analysis/book.html.

White, L. (1985). The Acquisition of Parameterized grammars: Subjacency in Second Language Acquisition. Second Language Research, 1, 1-17.

Youssef, A.\& Mazurkewish, I.(1998) . The Acquisition of English Metrical Parameters and Syllable structure by Adult Native Speakers of Egyptian Arabic (Cairene Dialect). In S. Flynn \& G. Martohardjono et al. (Eds), The Generative Study of Second Language Acquisition (303-331). Mahwa, N.J : Lawrence Erlbaum Assoc . 
(Tables \& Figures)

Table 1: The Metrical Parameters Settings for Arabic and English with their Default Values

\begin{tabular}{|l|l|l|l|l|}
\hline & Parameters & Arabic & English & $\begin{array}{l}\text { D\&K's } \\
\text { Default } \\
\text { Values }\end{array}$ \\
\hline P2 & Feet are & Binary & Binary & Unbounded \\
\hline P3 & Feet are built from the & Left & Right & Left \\
\hline P4 & Feet are strong on the & Left & Left & Left \\
\hline P5 & Feet are quantity-sensitive & Yes & Yes & No \\
\hline P6 & Feet are QS to the & Rhyme & Rhyme & Rhyme \\
\hline P8A & $\begin{array}{l}\text { There is an extrametrical } \\
\text { syllable }\end{array}$ & Yes & Yes & No \\
\hline P8B & $\begin{array}{l}\text { There is an extrametrical } \\
\text { segment }\end{array}$ & Yes & Yes & No \\
\hline P8 & It is extrametrical on the & Right & Right & ------ \\
\hline
\end{tabular}

Table 2: The percentages of correct and Incorrect Stress Patterns in class 1 and 2

\begin{tabular}{|c|c|c|c|}
\hline \multicolumn{2}{|c|}{ Class \& Task } & \multicolumn{2}{c|}{ Incorrect \% } \\
\cline { 3 - 4 } \multicolumn{2}{|c|}{} & penult & final \\
\hline Class1 & wpro & 25.5 & 17 \\
\cline { 2 - 4 } & spro & 20 & 15 \\
\cline { 2 - 4 } & wper & 23 & 35 \\
\cline { 2 - 4 } & sper & 23.5 & 39.5 \\
\hline Class2 & wpro & 42 & 14 \\
\cline { 2 - 4 } & spro & 36 & 16 \\
\cline { 2 - 4 } & wper & 30 & 48 \\
\cline { 2 - 4 } & sper & 36 & 40 \\
\hline
\end{tabular}


Table 3: The percentages of correct and Incorrect Stress Patterns in Class $(3,4,5)$

\begin{tabular}{|l|l|l|l|}
\hline \multicolumn{2}{|c|}{ Class \& Task } & \multicolumn{2}{|c|}{ Incorrect \% } \\
\cline { 3 - 4 } \multicolumn{2}{|c|}{} & $\begin{array}{l}\text { Ante- } \\
\text { penult }\end{array}$ & final \\
\hline Class3 & wpro & 46.66 & 13.34 \\
\cline { 2 - 4 } & spro & 60 & 3.66 \\
\cline { 2 - 4 } & wper & 20 & 23.34 \\
\cline { 2 - 4 } & sper & 21 & 29.66 \\
\hline Class4 & wpro & 42.5 & 5 \\
\cline { 2 - 4 } & spro & 41 & 14 \\
\cline { 2 - 4 } & wper & 22.5 & 30 \\
\cline { 2 - 4 } & sper & 25 & 35 \\
\hline Class5 & wpro & 35 & 5 \\
\cline { 2 - 4 } & spro & 40 & 10 \\
\cline { 2 - 4 } & wper & 30 & 47.5 \\
\cline { 2 - 4 } & sper & 32 & 43 \\
\hline
\end{tabular}

Table 4: The Percentages of Correct and Incorrect Stress Patterns in Class 6 and 7

\begin{tabular}{|c|c|c|c|}
\hline \multirow{2}{*}{\multicolumn{2}{|c|}{$\begin{array}{c}\text { Correct \% } \\
\text { Class \& Task }\end{array}$}} & \multicolumn{2}{|c|}{ Incorrect \% } \\
\hline & & Antepend & penult \\
\hline \multirow[t]{4}{*}{ Class 6} & wpro & - & 57.5 \\
\hline & spro & - & 52.5 \\
\hline & wper & - & 32.5 \\
\hline & sper & - & 20 \\
\hline \multirow[t]{4}{*}{ Class7 } & wpro & 14 & 29.34 \\
\hline & spro & 9.66 & 60 \\
\hline & wper & 30.34 & 16.66 \\
\hline & sper & 46.34 & 10 \\
\hline
\end{tabular}


Table 5: The percentages of the common incorrect responses of stress placement for learners' word production and perception in all the classes

\begin{tabular}{|l|l|l|l|l|}
\hline $\begin{array}{l}\text { Class \& correct stress } \\
\text { placement }\end{array}$ & $\begin{array}{l}\text { Common } \\
\text { incorrect } \\
\text { stress } \\
\text { placement }\end{array}$ & $\begin{array}{l}\text { Production } \\
\%\end{array}$ & $\begin{array}{l}\text { Common } \\
\text { incorrect } \\
\text { stress } \\
\text { placement }\end{array}$ & $\begin{array}{l}\text { Perception } \\
\%\end{array}$ \\
\hline 1(N-antepenult stress & penult & 22.75 & final & 37.25 \\
\cline { 1 - 1 } 2 2(V\&N-antepenult stress) & & 39 & & 44 \\
\hline 3 (N-penult stress) & antepenult & 53.22 & final & 26.5 \\
\cline { 1 - 1 } & & 41.75 & & 32.4 \\
\cline { 1 - 1 } 4 ( N-penult stress) & & 37.5 & & 45.25 \\
\hline 5 ( V-penult stress) & penult & 55 & penult & 26.25 \\
\hline 7 ( V-final stress) & penult & 44.67 & antepenult & 38.34 \\
\hline 7 ( N-final stress) & & & & \\
\hline
\end{tabular}


Table 6: The percentages of the learners' common incorrect responses and wrong values of the metrical parameters in both tasks for all the classes

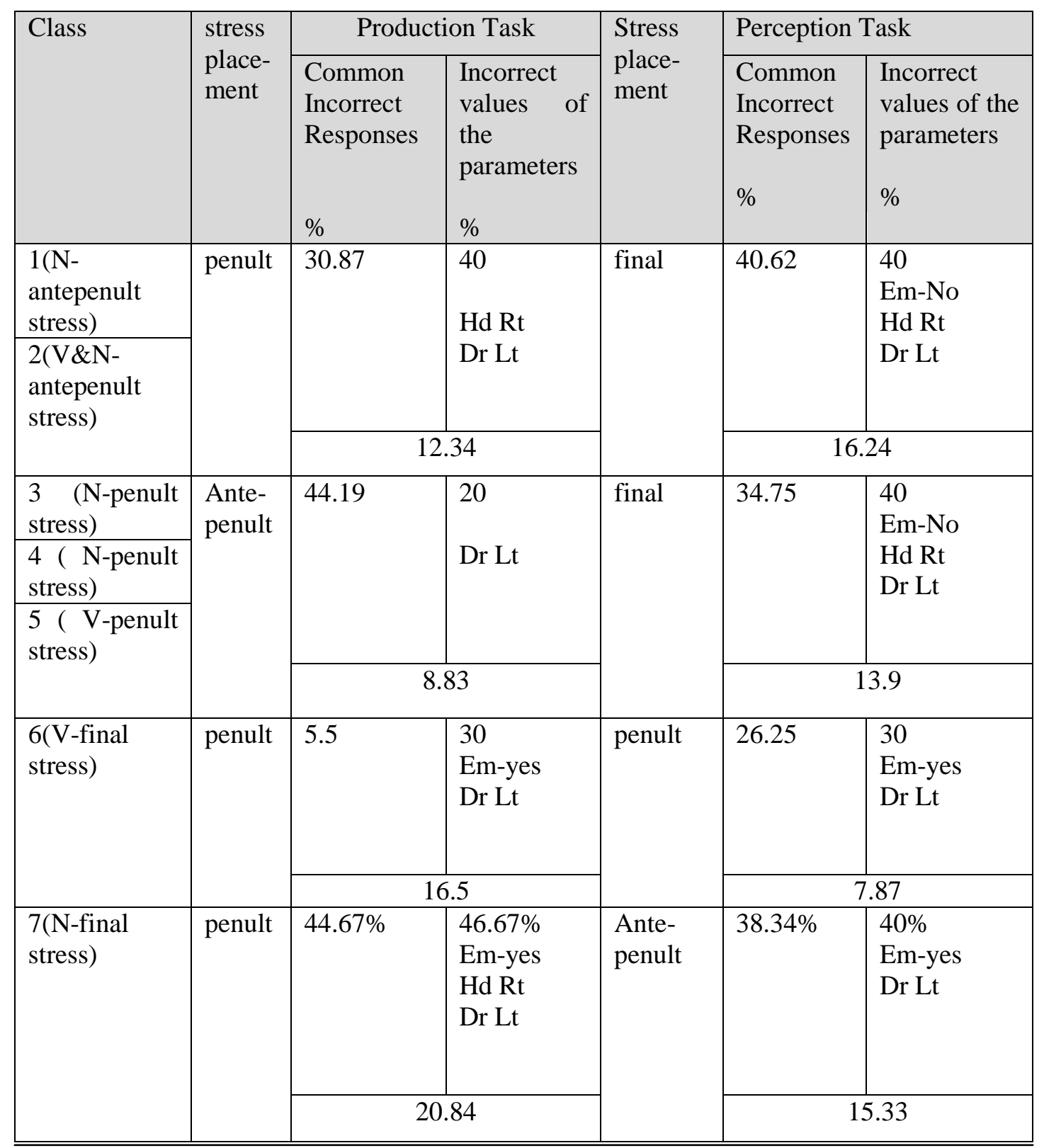


Table 7: The percentages of the ranking level kinds of the wrong metrical parameters used by Iraqi learners' common word stress production and perception in all the classes

\begin{tabular}{|c|c|c|c|c|c|}
\hline \multicolumn{2}{|c|}{$\begin{array}{l}\text { Kind of ranking level of } \\
\text { the wrong metrical } \\
\text { parameters }\end{array}$} & \multicolumn{2}{|c|}{$\begin{array}{c}\text { Production } \\
\qquad \%\end{array}$} & \multicolumn{2}{|c|}{$\begin{array}{l}\text { Perception } \\
\%\end{array}$} \\
\hline \multirow[t]{2}{*}{ Economy } & Embedding & 71.42 & \multirow{2}{*}{49.99} & 85.71 & \multirow{2}{*}{92.85} \\
\hline & Terminal & 28.57 & & 100 & \\
\hline \multirow{5}{*}{$\begin{array}{l}\text { Marked- } \\
\text { ness }\end{array}$} & $\mathrm{Lt}=\mathrm{Rt}$ & \multicolumn{2}{|l|}{7.14} & \multicolumn{2}{|l|}{71.42} \\
\hline & $\mathrm{Lt}>\mathrm{Rt}$ & \multicolumn{2}{|l|}{50} & \multicolumn{2}{|l|}{14.28} \\
\hline & $\mathrm{Rt}>\mathrm{Lt}$ & \multicolumn{2}{|l|}{14.28} & \multicolumn{2}{|l|}{0} \\
\hline & No $>$ Yes & \multicolumn{2}{|l|}{28.57} & \multicolumn{2}{|l|}{28.57} \\
\hline & Yes $>$ No & \multicolumn{2}{|l|}{0} & \multicolumn{2}{|l|}{71.42} \\
\hline
\end{tabular}




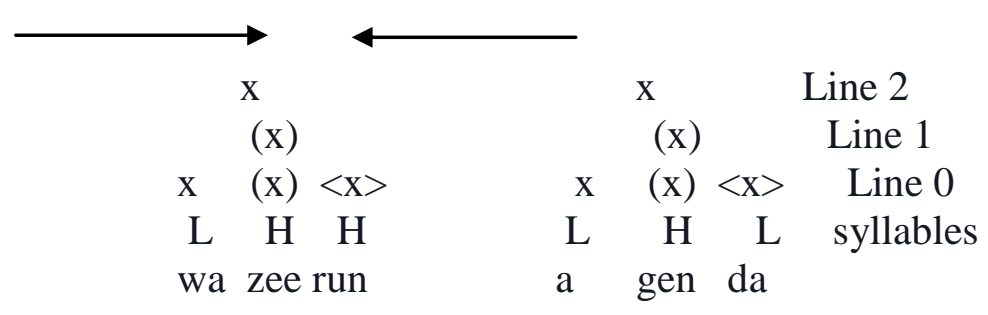

Figure 1: The Bracketed-Grid structure of metrical parameters of stress assignment in Arabic and English words

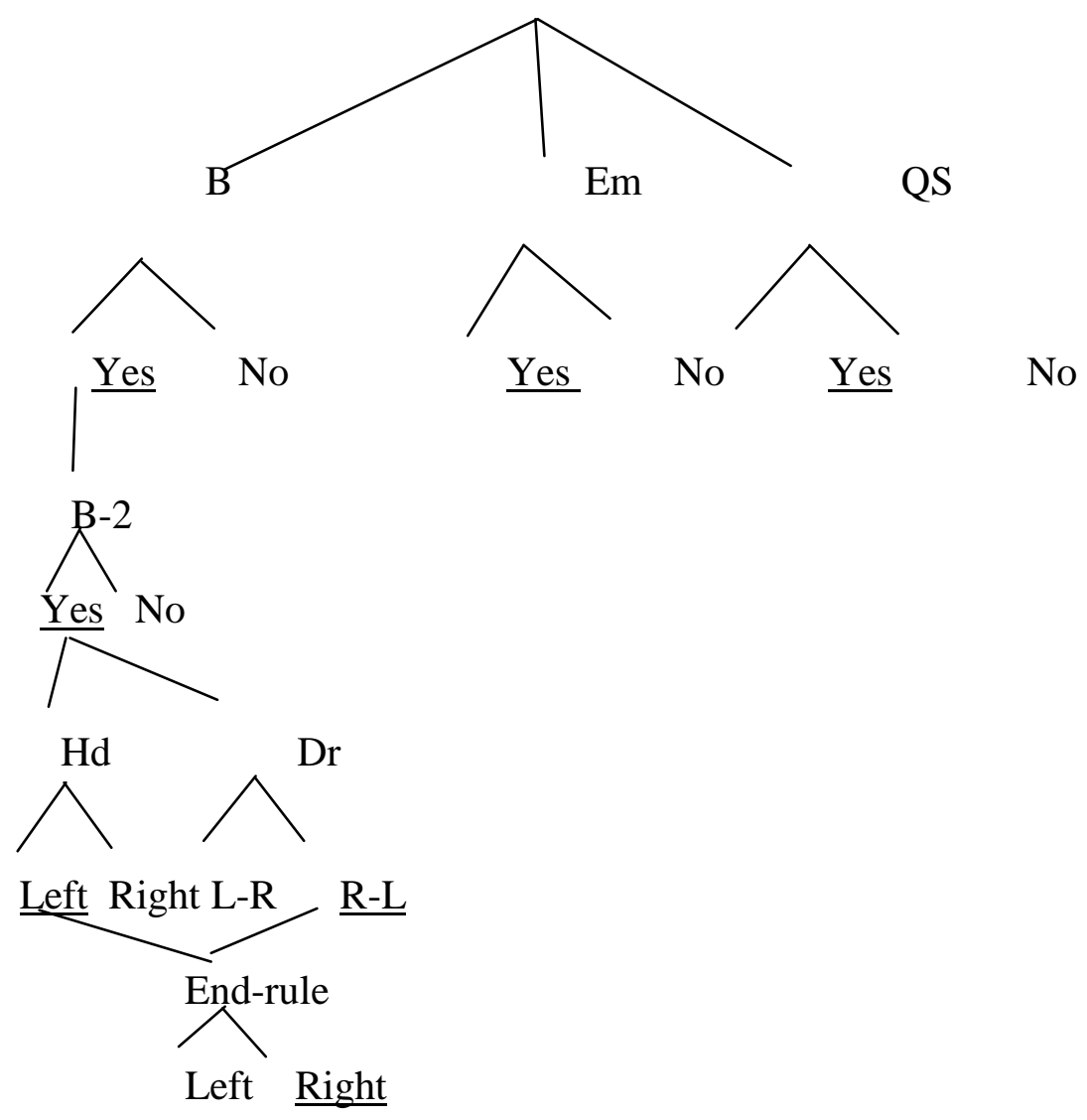

Figure 2: The PAP of Iraqi learners in learning L2 


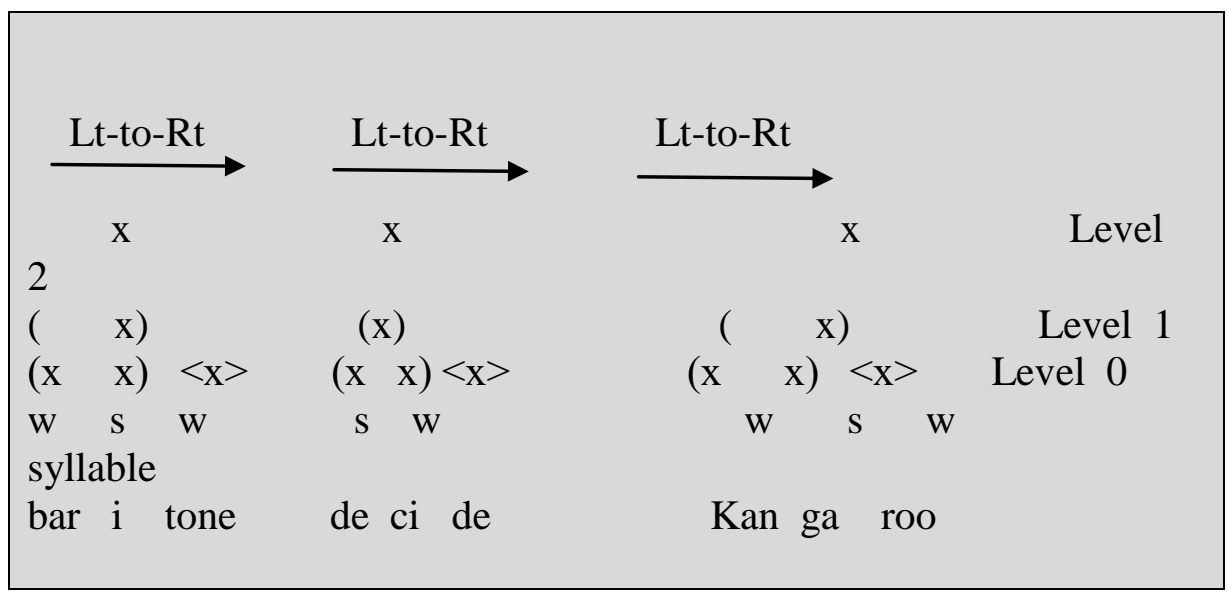

Figure 3: The syllable structure of the learners' production of the penult stress

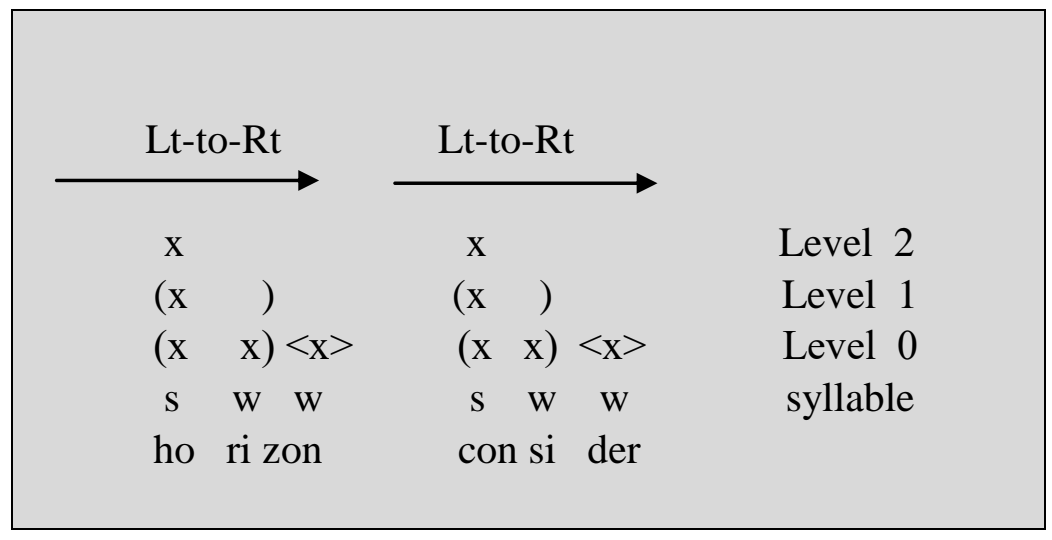

Figure 4: The syllable structure of the learners' production of the Antepenult stress 


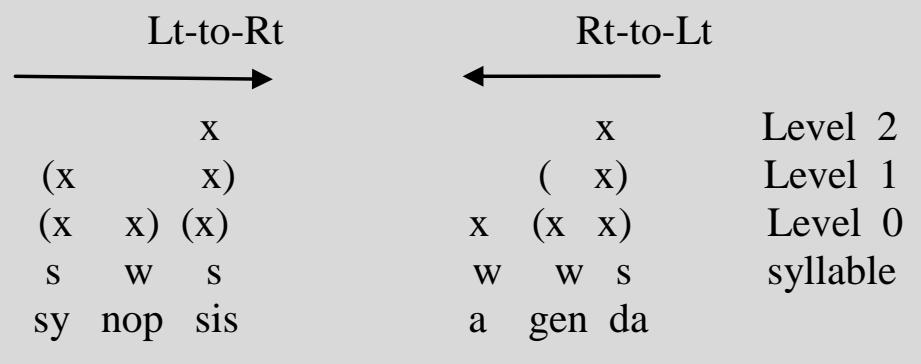

Figure 5: The syllable structure of the learners' perception of the final stress

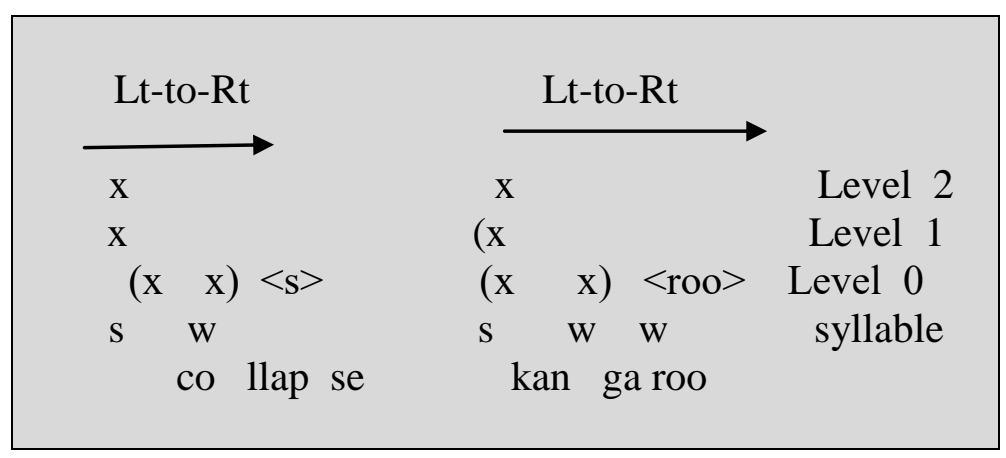

Figure 6: The syllable structure of the learners' perception of the penult and antepenult stress 